\title{
Using Explicit and Implicit Instruction to Develop Pragmatic Ability in Non-Urban Classrooms in South Africa
}

\author{
Phyllis Kaburise
}

phyllis.kaburise@univen.ac.za / phyllis.kaburise@gmail.com

\section{Doi:10.5901/mjss.2014.v5n23p1235}

\section{Abstract}

Language learners' pragmatic ability enables them to interact competently in communication events. Pragmatics main distinguishing feature from other branches of language study is that it portrays how language is used in real social interactions. Pragmatics ability has a broad base as it requires knowledge not only in theoretical content such as phonology, semantics, speech acts, but also in applied language subjects like sociolinguistics, cultural studies and communication. This inclusive nature of pragmatics poses some challenges in the type of instruction which will ensure the acquisition and demonstration of pragmatic competence. The debate is usually between teaching strategies falling under two paradigms of instructions - explicit and implicit. This is a reflective paper and its objective is to discuss two teaching activities role plays (implicit instruction) and elearning (explicit learning) as possible ways of enhancing English second language pragmatic development, in a rural classroom, in South Africa. The conclusion reached is that due to conceptual and practical challenges associated with role plays and e-learning, these approaches to pragmatic development may not produce dramatic results as may be wished.

Keywords: pragmatics, instruction, explicit, implicit, role play, e-learning

\section{Introduction}

Learning second or subsequent languages is fraught with issues internal and external to the student and to the classroom and the extensive literature on second language acquisition testifies to researchers' interest in the subject (Krashen, 1982; Bialystok, 1994; Ellis, 2005; Cook, 2008; Slabakova, 2010). Among the few undisputed facts in language study is the acceptance that competent performance in any communication event, in any language is determined by an array of skills, among them a person's pragmatic ability (Rueda, 2006; Gu, 2011; Mohammed, 2012). Ability in pragmatics enables learners of a language to demonstrate linguistic appropriate behavior in the unpredictable world of communication. Pragmatic ability is therefore an all-embracing ability which embodies competence in other aspects of language knowledge like phonology, syntax, semantics as well as topics in pragmatics like speech act theory, direct and indirect speech acts, inference, conversation principles, and relevance theory. These competences are coupled with background in applied studies like, sociolinguistics, psycholinguistics, non-verbal communication, second language acquisition, discourse analysis, cultural studies, communication studies and politeness theories. This extreme inclusive nature of pragmatics, while making it a vibrant and innovative branch of language studies has also invited questions as to whether it is in fact an autonomous area of language study. Kasper (1997) writes that despite this uncertainty, pragmatic competence is not extra, ornamental or subordinate to knowledge of the other more theoretical and traditional branches of language study, rather it is one's composite ability and the application of such ability in creating meaning in diverse communication environment. This facilitated the emergence of pragmatics as a separate branch of language studies with emphasizes on the usage of language.

The acceptance of this status of pragmatics has seen the recognition of appropriate communicative interaction as a significant indication of pragmatic competence and emphasis is placed on moving learners from classroom practice of target language forms to functional and unrehearsed language practice (Zheng \& Huang, 2010). This fact also highlights the societal aspect of language centering on language being a tool for socializing. Competent pragmatic behavior is, thus, in line with the reconceptualisation of language learning as an emerging social process situated in the larger context of social interactions. The classroom has also been redefined as a virtual social arena leading to an increased sensitivity to classroom discourse and interaction. Learning any language, hence, is inherently linked to learners' participation in various speech events, in varying settings, in and outside the classroom (Cekaitè, 2007; Wedin, 2010).

Acquiring of pragmatic competence by second language (L2) learners has received some attention (Soler, 2005; Tatsuki, 2005; Ji, 2008; Nikula, 2008; Yuang, 2012). This attention has been ascribed to the fact that L2 learners often 
show significant divergence in their theoretical knowledge and their performance in actual communication events. Hence, an advanced L2 user might not show equivalent pragmatic competence in executing and comprehending certain speech acts, in conversational functions, such as greetings and leave-taking, in refusing offers, declining invitations and in conversational management like back channeling and short responses (Eslami-Rasekh, 2005; Mohammed, 2012). Often, L2 users' misapplication of surface structure rules or pronouncing of words with strong first language (L1) accent are usually indulgently regarded as they usually only slow down the pace of the interaction as interlocutors mentally adjust in their bid to communicate and interpret each other's intentions (Kaburise, 2007). In such situations the more proficient users subconsciously apply communication organizing principles like the theory of speech acts (Searle, 1980), conversation maxims (Grice, 1989) and the relevance theory of Wilson \& Sperber (2005)to move the conversation along. Pragmatic idiosyncrasies however have more potential to offend as many speech acts have pragmatic conventional routines which simply must be mastered (Bardovi-Harlig \& Vellenga, 2012). These two authors report on a study they conducted that showed, for example, that routine formulaic pragmatic expressions like - no problem, excuse me, of course, nice to meet you, that'd be great, you must be joking, etc. - have the potential to cause consternation during interactions if not appropriately used. The potential of L2 users giving unintentional pragmatic offence has necessitated the call for instruction to develop such users' pragmatic ability, whether explicitly or implicitly.

\section{Rationale}

Atieh et al., (2014) reporting on a study into the type of instruction with the most impact on development of pragmatic ability examines as many as 37 different strategies and go on to rank them according to preference. The results show that role plays and implicit teaching of language functions are superior to use of computer programmes. These findings are quite startling in view of the role that computer- mediated language learning is playing in education globally. These results serve as the bases for the reflections in this paper.

\section{Theoretical Background}

The study of pragmatics came into its own right in the 1950s and 60s from the realization that meaning does not only reside in words and expressions but that there are other factors which mitigate on meaning. The 'literal' or 'natural' meaning is represented by the agreed value societies that use that language have invested in words and expressions (Searle, 1979; Grice, 1989). Therefore the word 'lady' has been ascribed certain properties by the users of the word and should the word appear in a sentence anywhere, the meaning would be commonly understood. Meaning of an expression can be taken as the composite meaning of all the words plus the significance of the expression's syntactic arrangement; this captures the syntactic and semantic meaning of expressions or the 'natural' or 'literal'. The realization, however, that meaning in communication or in language use, goes beyond this, laid the foundation for pragmatics as a recognized separate branch of language studies (Searle, 1980).

Meaning at the literal or natural level, therefore does not completely capture the intention of interlocutors but an extra level of meaning is also implied, during communication, which is dependent on the context information (Bach, 2014). Contextual information is usually categorized as physical, epistemic, linguistic and social. Physical context is inclusive of all physical attributes (time, place, objects around and on-going actions, etc.) in relation to the situation of the interaction. Epistemic context refers to the world and personal encyclopedic knowledge shared by the interlocutors. Linguistic context includes the choices and structural arrangement of the words and phrases as well as phonological cues while social context takes cognizance of the social profile of interlocutors as well the relationship between them. Meaning in pragmatics, therefore is not intrinsic to the linguistic words but rather results from the interaction of these words and expressions with the context in which they are uttered.

The notion that pragmatics embodies situational or contextual variables attributes some vibrancy, innovativeness but also some impermanency to pragmatic meaning as changes in the situation affect an utterance's meaning. One implication of this is that interlocutors' pragmatic ability is also dependent on competence on the multiplicity of factors constituting context or situation in conversation events. Hence an expression like - It is dark in here - assumes different communicative meanings depending on contextual details like, the time of the day that it was uttered, the location and who the interlocutors are and their status. The necessity to factor in all aspects of context - physical, epistemic, linguistic and social - into interpreting utterances has naturally broadened the base for pragmatic competence. This has resulted in the need for interlocutors, therefore to be versed not only in pure language and pragmatic topics but also in applied language studies, since knowledge in these subjects provide the contextual information needed to interpret utterances.

An implication of this extreme inclusivity of pragmatics is that it has also created challenges for its acquisition, 
particularly by L2 students. Attempts to find a high-impact acquisition approach have motivated researchers to investigate various aspects of pragmatics, such as development of various speech acts (Bayat, 2013). These investigations have shown that the more theoretical aspects of language development like surface structure of utterances benefit substantially from explicit teaching, even for L1 users, however acquiring pragmatic ability by L2 learners has generated controversy as to the type of instruction which is most relevant (Soler, 2005; Barron \& Celaya, 2010; Soler \& Pitarch, 2010; Mohammed, 2012). Parents, peers and ordinary everyday linguistic interaction act as models and corrective measures in pragmatic language development for L1 users, however, such monitoring devices are usually not afforded to English L2 learners in low-socioeconomic rural communities. That pragmatic ability is not self-developing or intuitive has led to the acceptance that pragmatic awareness needs some kind of instruction. Two questions have arisen from this fact - what kind of metapragmatic topics should be focused upon and what type of instruction would ensure the maximum impact on pragmatic development? Discussions of these two questions form the gist of the next sections.

As indicated earlier a background in a range of topics has been identified as contributors to pragmatic competence, among them, theoretical as well as allied subjects. Among these topics, speech act theory has received much attention among L2 researchers (Takahashi, 2010). One reason given by Spanoudis et al., (in Yuang 2012) is that speech acts are regarded as the most complex aspect of language, for they require collaboration or synergy of all levels of language and also draw on the interaction between cognition and language. Bayat (2013) notes that speech acts are the focus of foreign language teaching because of 'usage problems faced by people of different cultures' ( $p$ 213). The substantial proportion of successful communication being embodied in interlocutors' exploitation of speech acts also explains the attention paid to acquisition of various speech acts (Wishhorn, 2000). This is also the justification for our discussions to dwell on L2 learners' mastery of speech acts.

Development of L2 learners' pragmatic ability therefore, rests substantially on their handling of speech acts. A 'speech act' is an attempt to do something purely by speaking (Karthik, 2013). During an interaction there are many intentions and actions embodied in speaking. For example, words make a promise, a threat, a request, a complaint, an offer, a command or make pronouncements. Each of these is a particular speech act depending on the context surrounding the utterance. The main principle in speech act is 'speaking implies doing' or 'saying is doing' (Bayat, 2013; Karthik, 2013). Communication is accomplished when speakers are able to articulate their intentions and hearers are able to correctly interpret the intentions. To do this the interlocutors must be appropriate in their utterances by choosing correct words, arranging them correctly and vocalizing them correctly, all of which should be accompanied by appropriate gestures after taking cognizance of the context. Should any of these processes be omitted, miscommunication can occur and when this occurs interlocutors' intentions may be misread. In addition, cultural and social offence may be given, the exchange may appear abrupt and negative personal judgments may be made about the interlocutors. Handling of speech acts is therefore a significant indication of a person's pragmatic ability, of a person's mastery of a language, L1 or subsequent ones.

The second part of the question asked earlier was on the type of instruction that enhances pragmatic competence - implicit or explicit. A discussion of these paradigms of instruction is undertaken in the sections following.

Implicit learning is "learning without conscious attention or awareness" (Brown, 2007, p 291). This process involves exposing learners to various input and they deduce underlying content, rules, and in the case of speech acts, their appropriate production and use during communication events. The underlying assumption therefore is that learners' interaction in these different communication events will encourage critical analyses of the process of verbal interactions and the use of speech acts, in particular, and the results will be applied by the learners in their own language behavior. One method of implicitly instructing in the classroom for speech act development, which is also highly recommended by researchers like, Liu \& Ding (2009), Atieh et al. (2014) is role play. This activity facilitates L2 students' movement from being learners to active users of the language. They are seen as not only ways of bridging the gap between the classroom and the real world but they also introduce a variety of ways to make the whole language learning process more pragmatic (Liu \& Ding, 2009). Ladousse (2004: 7) categorises role play as "perhaps the most flexible technique in the range" of communicative strategies, believing that if utilised effectively, teachers can meet an infinite variety of linguistic needs. A role play is a highly flexible learning activity which has a wide scope for variation and imagination for its users. Here, peer learning is encouraged and sharing of responsibility between teacher and the learner, in the learning process, takes place. For the shy and less advanced students, role-play helps by providing a mask, where learners with difficulty in conversation are liberated. In their assumed roles, students become confident as they suppress other personality inhibitions (Ladousse, 2004).

Explicit instruction involves formalized content where main tenets of a subject are portioned into discrete units and learners are taken through these units. In pragmatics, explicit instruction would involve instruction in the many diverse aspects inclusive in pragmatic competence -theoretical and applied language studies. This comprehensive array of 
topics would ensure learners have the requisite knowledge and skills to construct utterances in accordance with norms of surface structural and of communication. The debate surrounding the most beneficial instruction has been joined by the inclusion of e-learning strategies for L2 instruction (Marzban, 2011; Kamberi, 2013; Dina \& Ciornei, 2013).

E-learning is understood to mean either implicit or explicit learning involving the use of computer programmes. Today the use of multimedia, the internet (especially the World Wide Web) and various forms of distance learning are wide spread. Computer-assisted language learning (CALL) has come into education along with the increasing presence of multimedia in the lives of those forming part of the global village. CALL is an approach to learning both L1 and L2 where computer and computer-based resources such as the Internet are used to present, reinforce and assess materials to be learned in the classroom. It usually includes a substantial interactive component and except for self-study software, CALL should complement teacher instruction and not replace it. The particular strength of CALL software programmes has been the opportunity they afford learners to drill and practice specific language concepts in controlled environments, provide more stimulating course materials and to cater for variety in learning styles. Hence, CALL has been seen to be successful in supporting discrete skills, for example, recognition of speech acts (Chiu et al., 2007); vocabulary learning (Ma, 2008); writing skills (Al-Menei, 2008); relative clauses (Romeo, 2008); reading comprehension (Marzban, 2011). Studies have also investigated for example, the impact on language development of the web application, blogging (Montero-Fleta, 2010). Posting and responding to blogs expands learners' repertoire of issues and people they can interact with, fostering cooperative learning and autonomy (Sun, 2009).

\section{Discussions}

Pragmatics ability, as noted is derived from interlocutors' knowledge of various theoretical and applied aspects of language and communication. To know a language, whether L1 or L2 means that we have knowledge of its features - for example, grammar, lexicon, morphological processes and pronunciation rules, among others. To know the process of communication means that, for example, users of any language know that conversation follows particular organisational pattern, such as, participants take turns; you wait to be recognized before you participate; that certain internal utterance structures are specific to certain intentions of speakers (hence you make a statement to provide information, an interrogative to elicit information and imperatives to demand certain causes of action)and that certain non-verbal behaviours (a smile, a frown, a shake of the head) correspond to certain intentions. L2 learners also know that the nature of the interaction will vary with factors such as social status, social and psychological distance, the level of 'face saving' involved in the event and the amount of directness and indirectness wanted in a speech act.

Background in these skills and knowledge must be in place for interlocutors to be declared pragmatically competent. The questions at this juncture are -what kind of instruction will ensure this for learners in English second language acquisition situations such as those that exist in low socio-economic areas, such as in Venda? What would ensure that such learners develop pragmatic competence?

Implicit instruction, as demonstrated, for example, by role plays have advantages. Some of these benefits can be summarised as - encouraging talking, better performance, transfer of concepts learnt in class, learners enjoy the activity, weak students are motivated into participating, give practice in real language structures and a less threatening language environment is created. These benefits do not, however nullify some disadvantages - lack of resources to set up the activities, too much preparation time, discipline problems as learners do not see the activities as proper teaching, activity dominated by learners who are fluent in English, difficult to create a real atmosphere, activity not useful because of low levels of proficiency, some language topics cannot be role played and difficulty in assessing individual performance (Kaburise, 2014).

In view of these identified advantages and disadvantages, role plays as an activity for enhancing pragmatic competence has to be carefully analysed, for example, in the context of South African English L2 language teaching. Role plays are most effective in 'open' system of instruction. Such learning context allows for teacher creativity and autonomy as role plays can go in any direction. Rigidly structured role plays degenerate into drills and rehearsed dramas and the essence of interactiveness, realism and unpredictability of communication events are then lost. Pragmatic competence is manifested in learners' ability, for example, to respond appropriately to the changing speech acts utilised in normal communication. However the very structured South African National Curriculum Statements (NCS) reduces teachers' ability to introduce innovation and realism into the classroom. The assessment requirements for Grade 12 are a perfect illustration of the above point. As many as twelve nationally prescribed assessment tasks are required for the calculation of continuous assessment (CASS) marks. These are school as well as provincially moderated assessment tasks. During informal discussions with teachers of Grade 12 English First Additional Language, they dwell on their inability to combine the demands of administering the various CASS tasks and their normal teaching. Discontent is 
directed mainly at the volume and variety of tasks that make up the Grade 12 CASS marks. This volume of tasks and their administration, Grade 12 teachers feel adversely affect the balance which should exist between assessment, new content and innovative pedagogies. Where there are time management challenges and there is tension between CASS and classroom teaching, classroom teaching is disadvantaged or sacrificed for teachers to adhere to provincial or national requirements. In this context, teachers are likely to sacrifice pedagogies which require extra resources, preparation and cannot be directly or objectively assessed, like role plays.

Assessment of pragmatic competence is another unresolved aspect of pragmatic instruction. Teachers who do decide to incorporate pragmatic enhancement activities, such as role plays, express concern about assessing such activities in an assessment-oriented curriculum like the South African NCS. In implicit instruction in pragmatics, although we can claim that this approach offers learners the opportunity for observing, understanding and producing speech acts, challenges exist in objectively evaluating learners (Soler \& Pitarch, 2010). The usual practice in assessing pragmatic competence is through Multiple-choice Discourse Completion Tests (MDCT), Discourse Completion Tests (DCT) Written Discourse Completion Test (WDCT). These forms of assessments have been used effectively with various aspects of pragmatics, however, concerns have been raised as to their suitability with assessing performance of speech acts (Cohen, 2010; Soler \& Pitarch, 2010; Aufa, 2013). One main feature of verbal communications is that they are unpredictable, hence the direction a conversation may take and the speech acts required are unpredictable. Even the sequential progression of communication cannot be foretold. This makes assessing of pragmatic interactions challenging and even more so when they form part of nationally required CASS marks in South Africa.

Effective role-plays require a certain caliber of teachers, supporting teaching styles as well as students. Criticism against the level of rural teachers' competence in English, and their low ability to model the language is, constantly, voiced in South Africa (Krugel \& Fourie, 2014). These teachers, lacking content background and confidence in the language of instruction prefer more predictable pedagogy as they have better control in such environments. Kamper (2008) notes that in this environment, 'poverty pedagogy' is the order of the day, not interactive pragmatic approaches, like role plays. Pragmatic sophistication is at a higher level in language acquisition, for L2 learners this comes about from hearing model target language utterances, interacting with the language and innovatively using the language, hence, controlling the language and not the reverse. Role plays or any other pragmatic-development teaching strategy for L2 learning needs that flexibility, room for maneuvering to make the language a tool for communication in real life. Teaching and learning in low-socioeconomic classrooms like those in Venda do not encourage this.

E-learning can, to a certain degree, introduce an interactive slant to $L 2$ teaching and learning. E-learning increases opportunities and motivation to communicate in English, video conferencing, virtual classrooms and web page authoring. Research suggests that computer-mediated communication (CMC) encourages English L2 learners to take risks with language, to learn from others and encourage creativity with language structures (Marzban, 2011). In spite of these advantages, using e-learning strategies specifically for increasing sophistication, in speech acts for L2 user, within the linguistic background of places like Venda has not been the focus of much study and of the results of the few studies in similar contexts have not been conclusive (Kasper and Rose 2002).

One of the implications of these inconclusive results of e-learning is that raising pragmatic awareness of L2 learners must be governed by their individual situations. In other words, the dynamic and unpredictable nature of communication is governed by individual context factors which are extremely difficult to be captured by programme designers not familiar with the context of the learners. Verbal interactions involving speech acts are subjected to variables and even in $\mathrm{CMC}$ only some of these variables can be factored. For example, how conversant are programme writers with life in a rural village in the Limpopo Province in South Africa? How can learners in such a location have an 'authentic' interaction with pre-designed programmes? Similar issues are raised by Kasper \& Rose (2002) and Rueda (2006). Their concerns were not about e-learning per se, although they were also concerned about authentic opportunities to practice language.

Although it can be argued that there are softwares on the market which could allow teachers to create contextrelevant computer-based course materials with little or no computer programming, this is a far-fetched phenomenon for teachers in the rural areas of Limpopo. One such authoring programme is the HyperCard from Macintosh which was advertised as very easy to use and can be directly applied to many aspects of instruction for every day classroom topics. An attempt to design interactive communicative course materials with this authoring programme clearly indicated the need for users to have more than basic programming skills as well as supportive networks (Ghasemi, et al., 2011). This process, hence, is beyond the caliber of teachers in most rural areas. In addition, the characteristics of learners from rural low-socioeconomic communities have a bearing on the level of pragmatic competence they can achieve. Features like the learners' first language and their proficiency in it, age, the target language, educational context and the status of the target language in the wider community all have bearing on the pragmatic levels achievable (Rueda, 2006). Such 
conditions affect the quality and authenticity of input learners receive both during role plays and in e-learning.

These challenges are compounded by obstacles which are mainly financial and technical in nature. Some problems are related quite naturally to the acquisition of computers, software, telephone lines and other related expenses and teachers', learners' and support staff's lack of knowledge of computers. Technical challenges include the fact that computers due to the limitations of their artificial intelligence, computer technology is not as adaptable to various linguistic contexts like teachers are. This means teachers should see computers as supplementing their instruction; this some teachers, particularly those in rural areas see as an extra demand, responsibility and a complication in their lives.

A summary of our discussions show that development of pragmatic ability does not stem from activities which can be categorized as either explicit or implicit instruction. A better approach is to regard these two types of instruction as on a continuum, starting with activities for explicit instruction which are supported by implicit activities to allow learners to interact with interlocutors in real communication events. This means the presence of a teacher who would instruct in the metapragmatic areas and if possible with the assistance of the various computer software available on the market. Role plays then became the outward demonstration by the learners of their interactive ability. Such a synergy between the two types of instruction, however, may not always be possible in some language learning contexts, such as those that exist in rural contexts of Venda, in South Africa. The very structured NCS and the challenges associated with assessing pragmatic competence reduce teachers' willingness to include pragmatic-raising activities in the classroom. In addition, in rural communities with various forms of lacks, activities which involve extensive equipment, materials and investment pose challenges, and this will not only negatively affect the ability of role plays to provide authentic opportunities for practice in language use but also whether e-learning can be utilized.

\section{Conclusion}

Instruction, whether explicit or implicit, for pragmatic competence has generated much discussion. The issues at stake are the types of instruction which would provide a background, for learners, in the very broad base of pragmatic competence. Pragmatics competence defined, in these discussions, as learners' ability to appropriately interact in communication events shows some success from both types of instruction - implicit in the form of role plays and explicit in forms of e-learning. This low level of success has been achieved because of conceptual and practical challenges associated with the two instruction strategies selected for discussion and the complexities of developing pragmatic development, conditions pertaining in rural schools of Venda and requirements of the curriculum of South Africa.

\section{References}

Al-Menei, A. 2008. An investigation of the effect of computer-assisted writing instruction on EFL learners' ability. (Master's thesis)

Atieh.F., Tan, K. \&Subakir, M. 2014. An investigation of Iranian instructors' methods and techniques in teaching interlanguage pragmatics. Procedia: Social and Behavioral Sciences 11861 - 67

Bach, K. 2014. Routledge Encyclopedia of Philosophy. http://online.sfsu.edu/kbach/spchacts.html Accessed June, 2014

Bardovi-Harlig, K., \&Vellenga, H. 2012. The effect of instruction on conventional expressions in L2 pragmatics. System 40, 77 - 89.

Barron, J. \& Celaya, M. 2010. Developing pragmatic fluency in an EFL context. EUROSA, 10. John Benjamins.

Bayat, N. 2013. A study on the use of speech acts. Procedia: Social and Behavioral Sciences 70, p. 213 - 221

Bialystok, E. 1994. Analysis and control in the development of second language proficiency. Studies in Second Language Acquisition, 16, 2, $157-168$.

Brown, D. 2007. Principles of language learning and teaching. Pearson Longman.

Cekaitè, A. 2007. A child's development of interactional competence in a Swedish L2 classroom. The Modern Language Journal, 9, 1, 45 $-62$.

Chiu, Tsuo-Lin, Liou, Hsien-chin, Yeh, \& Yuli.2007. A study of web-based oral activities enhanced by automatic speech recognition for EFL college learning. In Al-Mansour, N., Al-Shorman, A. The effect of computer-assisted instruction on Saudi University students' learning of English, Languages and Translation, 2012, 24, 51 - 56

Cook, V. 2008. Second language learning and language teaching. London: Arnold.

Dina, A. \& Ciornei, S. 2013. The advantages and disadvantages of computer assisted language learning and teaching for foreign languages. Procedia: Social and Behavioral Sciences 76, p. 248 - 252.

Ellis, R. 2005. Measuring implicit and explicit knowledge of a second language. Studies in Second Language Acquisition, 27, 2, 141 172.

Eslami-Rasekh, Z. 2005. Raising the pragmatic awareness of language learners. ELT Journal, 59, 3. Oxford University Press.

Ghasemi, B., Hashemi, M. and Bardine, S. 2011. The capabilities of computers for language learning. Procedia: Social and Behavioral Sciences 28, p. 58 - 62.

Grice, P. 1989. Studies in the way of words. Cambridge MA. Havard University Press. 
$\mathrm{Gu}, \mathrm{X}$. 2011. The effect of explicit and implicit instruction of request strategies. Intercultural Communication Studies XX:1

Ji, P. 2008. Pragmatics and pedagogy: an examination of college English teaching in China. (PHD Thesis) University of Sydney , Australia.

Kaburise, P. 2007.Conversation principles and second language utterances. Per Linguam, 23, 1.1 - 15.

Kaburise, P. 2012. Making English communication Skills (ECS) at University of Venda more relevant. South African Journal of Higher Education, 26, 1.

Kamberi, L. 2013. Computer assisted versus classroom instruction: the big dilemma revisited. Procedia: Social and Behavioral Sciences 70, $1691-1695$

Kamper, G. 2008. A profile of effective leadership in some South African high poverty schools. South African Journal of Education, $28,1$. Pretoria.

Karthik, D. 2013. Pragmatics and language communication. The Criterion: an International Journal in English, IV, 3

Kasper, G. 1997. The role of pragmatics in language teaching education. In Bardovi-Harlig, K. \& Hartford, B. (eds). Beyond Methods: Components of second language Teacher Education. New York: McGraw-Hill.

Krashen, S. 1982. Principles and practice in second language acquisition. Pergamon Press.

Krugel, K. \&Fourie, E. 2014. Concerns for the language skills of South African learners and their teachers. International Journal of Education Science, 7.1, 219 - 228. Kamla-Raj

Ladousse, G.2004. Role play (p 7). Oxford. Oxford University Press.

Liu, F. \& Ding, Y. 2009. Role play in English language teaching. Asian social Science, 5, 10, 140 - 151.

$\mathrm{Ma}, \mathrm{Q}$. 2007. From monitoring users to controlling user actions: A new perspective on the user-centred approach to CALL. Computerassisted Language Learning, 20, 4, 297 - 321.

Marzban, A. 2011. Improvement of reading comprehension through computer-assisted language learning in Iranian intermediate EFL students. Procedia Computer Science, 3, 3 - 10

Mohammed, M. 2012. Teachability of pragmatic competence: The impact of explicit instruction on the development of Iraqi Freshman EFL learners' pragmatic competence. Basrah University

Montero-Fleta, B. \& Perez-Sabater, C. 2010. A research on blogging as a platform to enhance language skills. Procedia: Social and Behavioral Sciences 2, $773-777$.

Nikula, T. 2008. Learning pragmatics in content-based classroom. In Soler, E \& Martinez-Flor (eds). Investigating pragmatics in foreign language learning, teaching and testing. Bristol Buffalo, Toronto: Multilingual Matters.

Romeo, K. 2008. A web-based listening methodology for studying relative clauses. Computer-assisted language Learning, 21, 1, 51 -66.

Rueda, Y. 2006. Developing pragmatic competence in a foreign language.Theoretical Discussion Papers. Colombian Applied linguistics Journal, 8.

Searle, J. 1979. Literal meaning in Expressions and meaning. Cambridge, Cambridge University Press.

Searle, J. 1980. Background of meaning. In Searle, J., Keifer, F. \& Bierwisch, M. (eds) Speech act theory and pragmatics. Dordrecht Reidel.

Slabakova, R. 2010. Semantic Theory and Second language Acquisition. Annual Review of Applied Linguistics, 30, 231 - 247.

Soler, E. 2005. Does instruction work for learning pragmatics in the EFL context? System 33, 417 - 435. Elservier.

Soler, E. \& Pitarch, G. 2010. The effect of instruction on learners' pragmatic awareness: a focus on refusals. International Journal of English Studies, 10, 1, 65-80.

Spanoudis, G., Natsopoulos, D. \& Panayiotou, G. 2007. Mental verbs and pragmatic language difficulties. In Yuang, Y. 2012. Pragmatics perceptions and strategies in Chinese College English learning (PHD Thesis)

Sun, Y. 2009. Voice blog: An exploratory study of language learning. Language learning and Technology, 13, 2, 88 - 103.

Tatsuki, D. (ed). 2005. Pragmatics in language learning, theory and practice. Tokyo: JALT, The Japan Association for language teaching, Pragmatics Special Interest Group.

Wedin, A. 2010. A restricted curriculum for second language learners - a self-fulfilling teacher strategy? Language and Education, 24, 3 , $171-183$.

Wilson, D. \& Sperber, D. 2005. Relevance theory. In Horn, L., Ward G. (eds) Handbook of Pragmatics.Oxford Blackwell.

Wishhorn, J. 2000. Hedging your bets: L2 learners' acquisition of pragmatic devices in academic writing and computer-mediated discourse. Second Language Studies 19 (1), 119 - 148.

Yuang, Y. 2012. Pragmatics perceptions and strategies in Chinese College English learning (PHD Thesis)

Zheng, L. \& Huang, J. 2010. A study of Chinese EFL learners' pragmatic failures and implication for college English teaching. Polyglossia, 18, 41 - 54. 